\title{
Proton-controlled Action of an Imidazole as Electron Relay in a Photoredox Triad
}

\author{
Philipp Gotico ${ }^{1}$. Christian Herrero ${ }^{2}$ Stefano Protti ${ }^{3} \cdot$ Annamaria Quaranta $^{1} \cdot$ Sujitraj Sheth $^{1} \cdot$ Reza Fallahpour $^{4}$. \\ Rajaa Farran ${ }^{1,5} \cdot$ Zakaria Halime $^{2} \cdot$ Marie Sircoglou $^{2} \cdot$ Ally Aukauloo $^{2} \cdot$ Winfried Leibl $^{1}(\mathbb{C}$
}

Received: 9 August 2021 / Accepted: 18 December 2021 / Published online: 5 January 2022

(c) The Author(s), under exclusive licence to European Photochemistry Association, European Society for Photobiology 2022

\begin{abstract}
Electron relays play a crucial role for efficient light-induced activation by a photo-redox moiety of catalysts for multi-electronic transformations. Their insertion between the two units reduces detrimental energy transfer quenching while establishing at the same time unidirectional electron flow. This rectifying function allows charge accumulation necessary for catalysis. Mapping these events in photophysical studies is an important step towards the development of efficient molecular photocatalysts. Three modular complexes comprised of a Ru-chromophore, an imidazole electron relay function, and a terpyridine unit as coordination site for a metal ion were synthesized and the light-induced electron transfer events studied by laser flash photolysis. In all cases, formation of an imidazole radical by internal electron transfer to the oxidized chromophore was observed. The effect of added base evidenced that the reaction sequence depends strongly on the possibility for deprotonation of the imidazole function in a proton-coupled electron transfer process. In the complex with $\mathrm{Mn}^{\mathrm{II}}$ present as a proxy for a catalytic site, a strongly accelerated decay of the imidazole radical together with a decreased rate of back electron transfer from the external electron acceptor to the oxidized complex was observed. This transient formation of an imidazolyl radical is clear evidence for the function of the imidazole group as an electron relay. The implication of the imidazole proton and the external base for the kinetics and energetics of the electron trafficking is discussed.
\end{abstract}

\section{Graphical Abstract}

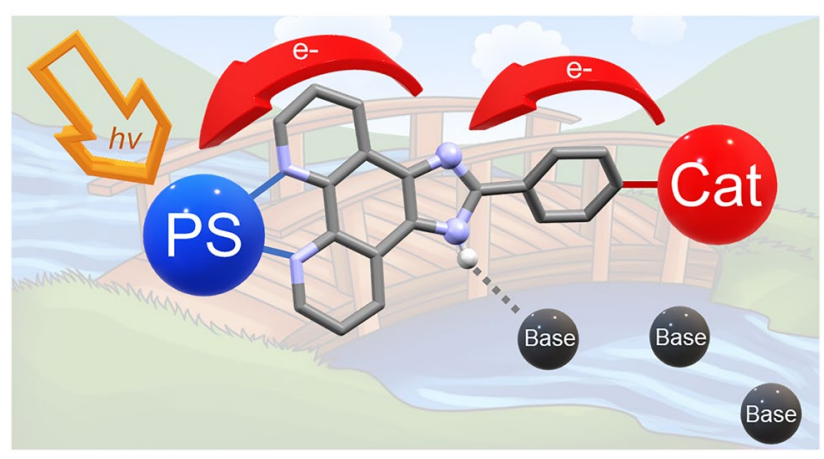

Keywords Artificial Photosynthesis · Molecular Triad · Electron Relay · Photoinduced Electron Transfer · Proton Transfer

Pushing the limits of flash photolysis to unravel the secrets of biological electron and proton transfer - a topical issue in honour of Klaus Brettel.

Winfried Leibl

winfried.leibl@cea.fr

Extended author information available on the last page of the article

\section{Introduction}

Light-induced electron transfer processes are primary events in photosynthesis where nature converts light energy and stores it in a chemical form. Understanding these processes is of particular relevance in the field of 
artificial photosynthesis. Indeed, chemists are aiming to couple a photo-redox cycle with a catalytic module that can perform multi-electron catalysis, for instance water oxidation, reduction of protons to $\mathrm{H}_{2}$ or reduction of $\mathrm{CO}_{2}$ to different carbon-based energy vectors. These aspects are remarkably orchestrated in Photosystem II (PSII), the enzyme that captures sunlight to extract electrons and protons from water $[1,2]$. Of particular interest for chemists seeking to mimic facets of PSII, is an electron relay positioned between the photoactive units, pigment $\mathrm{P}_{680}$, and the $\mathrm{Mn}_{4} \mathrm{Ca}$ oxygen evolving complex (OEC) [3]. The implication of such an intermediate electron donor in the reduction of $\mathrm{P}_{680}{ }^{+}$had been demonstrated by time-resolved absorption studies by Brettel et al. already in 1984, years before this electron relay has been identified as a tyrosine/ histidine pair [4]. This electron relay plays a crucial role by coupling the one-photon, one-electron photochemistry of the light absorber to multi-electronic catalysis by rapidly resetting the ground state (GS) of photogenerated oxidized $\mathrm{P}_{680}{ }^{+}$and transferring the oxidizing power to the OEC [5]. As it is not reduced by the excited state of the chromophores, this module also helps to avoid detrimental reverse photoinduced electron transfer (ET) to the oxidized OEC favoring charge accumulation at the catalytic center over charge annihilation between the catalytic and sensitizer units. Implementing such functionalities in chemical modular assemblies may help chemists to gain control over the directionality of electron transfer when developing a molecular artificial photosynthetic system. The importance of such an electron relay has already been shown by Mallouk et al. [6] with a photosensitizer coupled to a putative water-oxidizing complex where the authors discovered a noticeable improvement in the light-driven oxidation of water when a designed phenol-imidazole pair acting as an electron mediator was covalently tethered to colloidal iridium oxide particles as the water oxidation catalyst [6]. This work provided supportive ground that implementation of such a mimetic module borrowed from natural photosynthesis can indeed lead to further optimization of the water splitting in a photoelectrochemical cell. Photooxidation processes in biomimetic models of the tyrosine/histidine pair of PSII have been investigated in detail especially with respect to the mechanism of proton-coupled electron transfer involving this hydrogen-bonded couple [7-12]. On the other hand, different photoredox-catalyst molecular assemblies have been reported for the water activation process [13]. However, no direct spectroscopic evidence on the participation of an electron relay positioned in between the photoactive unit and the putative oxidative catalyst and the beneficial effect of such an electron relay in photocatalysis has yet been reported. Henceforth, it is evident that much effort is still needed to optimize the electron transfer processes in molecular photocatalyst assemblies.

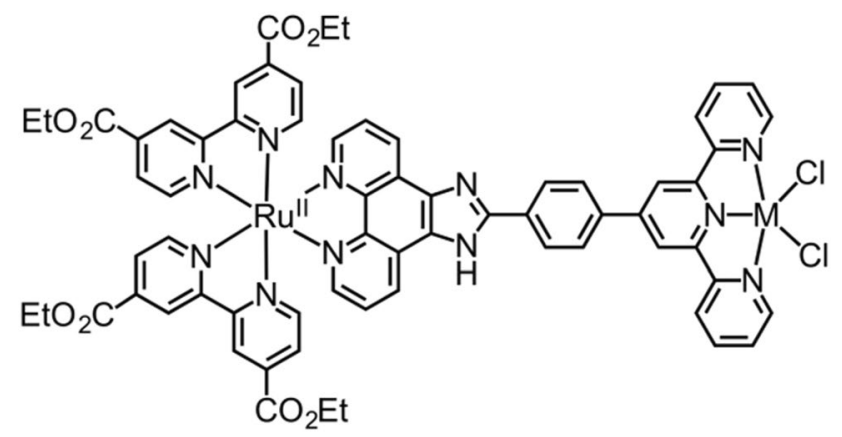

$1: M=$ none $; 2: M=M n ; 3: M=Z n$

Scheme 1. Structure of complexes used in this study

We found in a previous study that an imidazole (Im) group fused with a phenanthroline in the coordination sphere of a ruthenium(II) trisbipyridine complex was the locus of oxidation through an intramolecular ET to the photogenerated $\mathrm{Ru}$ (III) [14]. From this finding, we built a covalently linked ruthenium(II)-trisbipyridine-imidazoleterpyridine-manganese(II) complex where the latter, acting as the final electron donor site, is also known as a precursor for a water-oxidizing catalytic system $[15,16]$. However, when monitoring the light-induced ET processes using a laser flash photolysis technique, only a direct one-electron transfer from the $\mathrm{Mn}$ (II) center to the oxidized chromophore was detected [17]. We have pursued our effort to unravel the implication of a molecular electron relay in photosensitizer-redox-active-manganese complexes. In a previous study, we found that decorating the bipyridine ligands with ester functions acting as electron-withdrawing groups and inducing an anodic shift by $c a .160 \mathrm{mV}$ of the $\mathrm{Ru}^{\text {III/II }}$ redox couple led to the distinction of the imidazole redox activity in contrast with our previous models [18]. However, its participation in the oxidation of the Mn(II) center could not be established. In this work, our model includes the same three redox-active modules, with a high-potential intermediate redox station inserted between the photosensitizer and the manganese (II) module, but the Mn unit was connected via a phenyl spacer (see Scheme 1). We analyze in what follows the light-induced intramolecular ET processes in the absence and presence of a redox-active manganese (II) center as terminal electron donor, compounds $\mathbf{1}$ and $\mathbf{2}$ respectively (Scheme 1). We also replaced the $\mathrm{Mn}$ (II) ion in the terpyridine coordinating site by the redox-inactive $\mathrm{Zn}$ (II) ion as a reference compound 3. Our results highlight the crucial role of proton transfers at the level of the Im electron relay to allow the system to display a light-induced two-step electron hopping process. 


\section{Experimental methods}

\subsection{General}

Acetonitrile and methanol (Aldrich) were HPLC-grade. $\left[\mathrm{Ru}(\mathrm{bpy})_{3}\right] \mathrm{Cl}_{2},\left[\mathrm{Ru}\left(\mathrm{NH}_{3}\right)_{6}\right] \mathrm{Cl}_{3}$, pyridine, 2,6-lutidine, imidazole, and trifluoroacetic acid (TFA) from Sigma-Aldrich were used as received. Methyl viologen (Sigma-Aldrich) was used as the $\mathrm{PF}_{6}^{-}$salt. Water was Milli-Q quality (18.2 M $\Omega$ $\mathrm{cm})$.

\subsection{Synthesis of 1, 2, and 3}

The synthesis of the mononuclear Ru compound $\mathbf{1}$ was performed as previously described [17, 19]. Compounds 2 and 3 were obtained by metalation with $\mathrm{MnCl}_{2}$ or $\mathrm{ZnCl}_{2}$, respectively, as previously described $[17,18]$. Our synthetic strategy was to use a $\left[\mathrm{Ru}^{\mathrm{II}}\left(\mathrm{bpyCO}{ }_{2} \mathrm{Et}\right)_{2} \text { (phendione) }\right]^{2+}$ complex as convenient synthon for the incorporation of a photoactive unit as part of more complex systems [17]. Steck and Day condensation of this synthon with an aldehyde function yields an imidazole moiety fused to the phenanthroline unit.

\subsection{Electrochemical measurements}

Cyclic voltammetry (CV) measurements were performed in an electrochemical cell composed of a glassy carbon $(3 \mathrm{~mm}$ diameter) working electrode, $\mathrm{Ag} / \mathrm{AgNO}_{3}\left(10^{-2} \mathrm{M}\right)$ reference electrode, and a platinum wire counter electrode using a $\mathrm{CH}$ Instruments potentiostat (model 600E). Acetonitrile was used as a solvent and samples were prepared at a concentration of 0.5 or $1 \mathrm{mM}$. Tetrabutylammonium hexafluorophosphate (TBAP) was used as supporting electrolyte at a concentration of $100 \mathrm{mM}$. The solutions were purged with argon, and the cyclic voltammograms were measured at a scan rate of $100 \mathrm{mV} / \mathrm{s}$. The effect of added base was investigated using various concentrations of pyridine, lutidine or imidazole.

\subsection{Spectroscopic measurements}

UV-Visible spectra were recorded on a Specord 210 (Analytic Jena) spectrophotometer. Laser flash absorption transients were recoded with an Edinburgh Instruments laser flash photolysis system (LP920) incorporating a Continuum Surelite II Q-switched Nd:YAG laser and a Continuum OPO for sample excitation at $460 \mathrm{~nm}(\sim 5 \mathrm{~ns}$ pulse duration, energy $30 \mathrm{~mJ}$ ). The LP920 system is equipped with a $450 \mathrm{~W}$ Xenon arc lamp for the probe light and detection is performed either via a Czerny-Turner blazed $500 \mathrm{~nm}$ monochromator (bandwidth: $1-5 \mathrm{~nm}$ ) coupled with a Hamamatsu R928 photomultiplier tube (kinetic mode) or via a $500 \mathrm{~nm}$
Table 1 Redox potentials of $\mathbf{1 ,}, \mathbf{2}$, and $\mathbf{3}$ in $\mathrm{CH}_{3} \mathrm{CN}+0.1 \mathrm{M}$ TBAP as recorded by cyclic voltammetry on a glassy carbon electrode at a scan rate of $100 \mathrm{mV} . \mathrm{s}^{-1}\left(\Delta E_{\mathrm{p}} / \mathrm{mV}\right)$ vs. $\mathrm{Ag} / \mathrm{AgNO}_{3}$; (ferrocene couple $=0.13 \mathrm{~V}$ )

\begin{tabular}{lllll}
\hline Compound & $E_{1 / 2} \mathrm{Ru}^{\mathrm{III} / \mathrm{II}}$ & $E_{1 / 2} \mathrm{Im}^{+/ 0}$ & $E_{1 / 2} \mathrm{Mn}^{\mathrm{III} / \mathrm{II}}$ & $E_{1 / 2} \mathrm{Cl}^{+/ 0}$ \\
\hline 1 & $1.24(80)$ & $1.18^{[\mathrm{a}]}$ & - & - \\
2 & $1.25(110)$ & $1.21^{[\mathrm{a}]}$ & $0.5(120)$ & $1.09^{[\mathrm{a}]}$ \\
3 & $1.26(120)$ & $1.18^{[\mathrm{a}]}$ & - & - \\
TerpyMnCl$_{2}^{[\mathrm{b}]}$ & - & - & $0.63(150)$ & $1.04^{[\mathrm{a}]}$ \\
$\mathrm{KCl}^{[\mathrm{b}]}$ & - & - & - & $0.98^{[\mathrm{a}]}$ \\
\hline
\end{tabular}

${ }^{[\mathrm{a}]}$ This wave is irreversible, and the peak potential is reported. ${ }^{[\mathrm{b}]}$ In acetonitrile with $5 \% \mathrm{H}_{2} \mathrm{O}$. Attribution of all redox couples is based on comparison of $\mathrm{CV}$ data for the three complexes (Fig. S1, left; DPV measurements are also shown in Fig. S1, right) and the observed effect of external base (Fig. S16)

blazed spectrograph (bandwidth: $5 \mathrm{~nm}$ ) coupled with a water-cooled ICCD camera (Andor DH720; spectral mode). For all optical measurements, $10 \times 10 \mathrm{~mm}$ sealed cuvettes were used, and samples were purged with argon for $10 \mathrm{~min}$ prior to measurements.

\section{Results}

The cyclic voltammograms for compounds 1-3 are shown in Figure $\mathrm{S} 1$ and the redox potentials are collected in Table 1. For compound $\mathbf{1}$ on the anodic side, a first irreversible oxidation wave of the imidazole is recorded at $1.18 \mathrm{~V} v \mathrm{~s}$. Ag/ $\mathrm{AgNO}_{3}$, followed by the metal centered oxidation of the ruthenium (II) center at $1.24 \mathrm{~V}$. The $\mathrm{CV}$ of 2 shows three oxidation waves at $0.5 \mathrm{~V}, 1.21 \mathrm{~V}$ and $1.25 \mathrm{~V} v s \mathrm{Ag} / \mathrm{AgNO}_{3}$ with the first oxidation attributable to the $\mathrm{Mn}^{\mathrm{III}} / \mathrm{Mn}^{\mathrm{II}}$ couple based on the corresponding electrochemical properties of the reference terpy- $\mathrm{MnCl}_{2}$ (Fig. S2). An oxidation wave at $1.09 \mathrm{~V}$ is assigned to oxidation of the accompanying $\mathrm{Cl}^{-}$ion. The electrochemical properties of $\mathbf{3}$ are reminiscent of $\mathbf{1}$ with a slight increase in the $\mathrm{Ru}{ }^{\mathrm{III}} / \mathrm{Ru}^{\mathrm{II}}$ oxidation potential. According to the electrochemical data and neglecting for the moment work terms due to electrostatic interactions, the oxidation of the imidazole unit by $\mathrm{Ru}^{\mathrm{III}}$ seems thermodynamically possible in all complexes although the driving force is relatively small. The irreversibility of the redox wave for the imidazole group observed for all three complexes is attributed to proton loss upon oxidation which makes this wave also sensitive to the presence of external base as described later (Fig. S16).

A typical feature of the absorption spectra of complexes 1-3 (Fig. S3) is the MLCT absorption band of the Ruchromophore which is red-shifted by $c a .25 \mathrm{~nm}$ compared to non-substituted bipyridines due to the presence of the ester electron-withdrawing groups with a weak absorption tailing 
up to $600 \mathrm{~nm}$ [17]. The absorption band around $350 \mathrm{~nm}$ is sensitive to the protonation state of the imidazole and is attributed to an intra-ligand charge transfer transition involving the imidazole group [14]. The presence of the divalent ion in the terpyridine also affects this band implicating a certain degree of interaction. Mirroring the red-shift observed on the electronic absorption spectra, the emission maximum for the complexes occurs at 645-650 nm instead of $610 \mathrm{~nm}$ (Table S1) [18]. Compared to $\mathrm{Ru}(\mathrm{bpy})_{3}$, the emission lifetime is increased from 0.8 to $1-1.6 \mu$ s (Fig. S4) which can be related to the relocalization of the excited states towards the ester bearing bipyridine units. The coordination of $\mathrm{Mn}(\mathrm{II})$ in the terpyridine cavity leads to a decreased emission yield which is attributed to partial fast energy transfer from the $\mathrm{Ru}^{\mathrm{II}} *$ excited state to the terpyMn ${ }^{\mathrm{II}}$ unit. Due to the presence of the ester substituents and the phenyl spacer this energy transfer quenching is considerably attenuated compared to complexes without these features [18]. No emission quenching is observed in presence of the $\mathrm{Zn}$ (II) ion in the terpyridine cavity. The emission properties are summarized in Table S1.

Electron transfer processes for the compounds 1, 2, and $\mathbf{3}$ were studied by time-resolved absorption spectroscopy after excitation of the chromophore in the MLCT band in presence of methyl viologen (MV) as external electron acceptor. In Fig. 1a, kinetic traces of absorption changes at 440 and $605 \mathrm{~nm}$ in acetonitrile solution are displayed for the monometallic complex $\mathbf{1}$. These two wavelengths are usually used as spectroscopic probes for the recovery of the oxidized $\mathrm{Ru}^{\mathrm{III}}$ to $\mathrm{Ru}^{\mathrm{II}}$ and for the presence of the reduced state of the electron acceptor, $\mathrm{MV}^{\bullet+}$, respectively. It is observed that the bleaching due to the $\mathrm{Ru}^{\mathrm{III}}$ state at $440 \mathrm{~nm}$ disappears quickly with simultaneous build-up of a large absorption $\left(\Delta \varepsilon \approx 20,000 \mathrm{M}^{-1} \mathrm{~cm}^{-1}\right)$ at this wavelength. The transition is described by biphasic kinetics (1.8 and $8.5 \mu$ s) yielding an average apparent time constant of $4.6 \mu$ s (Fig. 1a, Fig. S5). At $605 \mathrm{~nm}$ the very fast $(<1 \mu \mathrm{s})$ rise of absorption due to formation of the $\mathrm{MV}^{\bullet+}$ radical $\left(\varepsilon_{605} \approx 13,900 \mathrm{M}^{-1} \mathrm{~cm}^{-1}\right)$ [20] is followed by a second phase of absorption increase with kinetics similar to the rate of $\mathrm{Ru}^{\mathrm{II}}$ recovery. These kinetic data indicate the oxidation of the imidazole group by intramolecular electron transfer to $\mathrm{Ru}^{\mathrm{III}}$ occurring with an apparent rate of $2.2 \times 10^{5} \mathrm{~s}^{-1}(4.6 \mu \mathrm{s})$ in neat $\mathrm{CH}_{3} \mathrm{CN}$.

The main spectral feature of the imidazole radical is clearly visible in the time-resolved spectra with a broad peak at $440 \mathrm{~nm}$ (Fig. 1b). However, the spectra are also contaminated by the absorption bands of the $\mathrm{MV}^{\bullet+}$ radical which shows a sharp peak at $390 \mathrm{~nm}$ and a broad maximum around $605 \mathrm{~nm}$. A clearer view of the imidazole radical was obtained when ruthenium hexamine $\left[\mathrm{Ru}\left(\mathrm{NH}_{3}\right)_{6}\right]^{3+}$ which presents only negligible absorption changes in the visible region, was used as an electron acceptor (Fig. 1b, inset). The obtained difference spectrum compares well with the
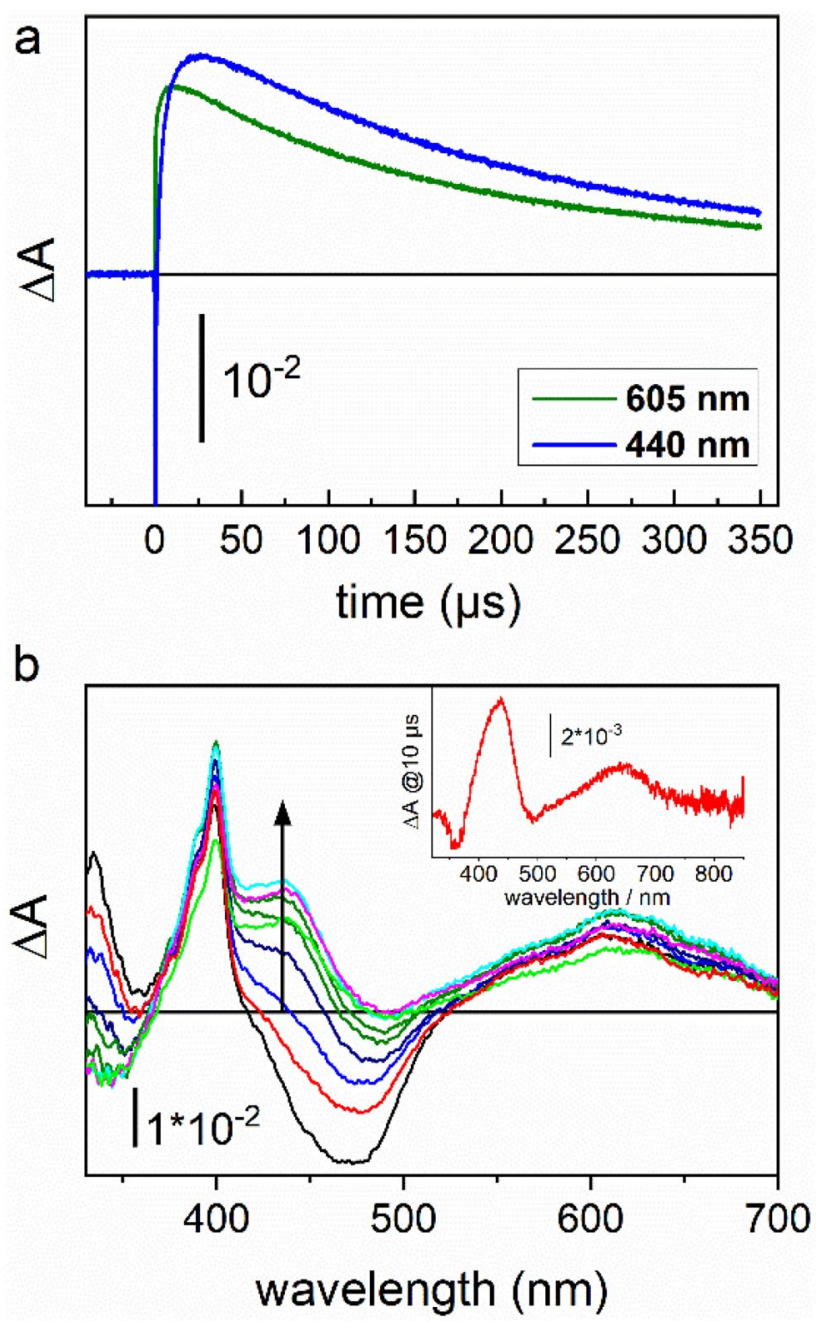

Fig. 1 a Transient absorption kinetics at $605 \mathrm{~nm}$ and at $440 \mathrm{~nm}$ (for kinetic analysis see Fig. S5). b Transient absorption spectra recorded between $200 \mathrm{~ns}$ and $100 \mu \mathrm{s}$ after laser excitation of complex 1 in $\mathrm{CH}_{3} \mathrm{CN}$ containing $25 \mathrm{mM} \mathrm{MV}{ }^{2+}$. Inset: spectrum taken $10 \mu \mathrm{s}$ after excitation in presence of $50 \mathrm{mM}$ ruthenium hexamine as electron acceptor in a $\mathrm{CH}_{3} \mathrm{CN} / \mathrm{H}_{2} \mathrm{O}$ mixture (1:1)

spectrum recorded with MV as electron acceptor after subtraction of $\mathrm{MV}^{\bullet+}$ contributions (Fig. S6). The spectrum is characterized by broad absorption bands around $440 \mathrm{~nm}$ and $650 \mathrm{~nm}^{1}$ consistent with the spectral features of an imidazolyl radical $\left(\mathrm{Im}^{\bullet}\right)[14,21-23]$. The large extinction coefficient at $440 \mathrm{~nm}\left(\Delta \varepsilon \approx 20,000 \mathrm{M}^{-1} \mathrm{~cm}^{-1}\right.$ by comparison with $\mathrm{MV}^{\bullet+}$ which has $\varepsilon_{397}=41,800 \mathrm{M}^{-1} \mathrm{~cm}^{-1}$ )[20] is also consistent with imidazolyl radical spectra in the literature [21]. On long times both the imidazolyl and $\mathrm{MV}^{\bullet+}$ radicals decay by charge recombination with a bimolecular diffusionlimited rate constant of $5.5 \times 10^{9} \mathrm{M}^{-1} \mathrm{~s}^{-1}$ (Fig. 1a).

\footnotetext{
1 The significant absorption of the imidazole radical around $650 \mathrm{~nm}$ is responsible for the slow additional rise in the $605 \mathrm{~nm}$ kinetic traces (Fig. 1a) which is no longer purely attributable to the MV radical.
} 


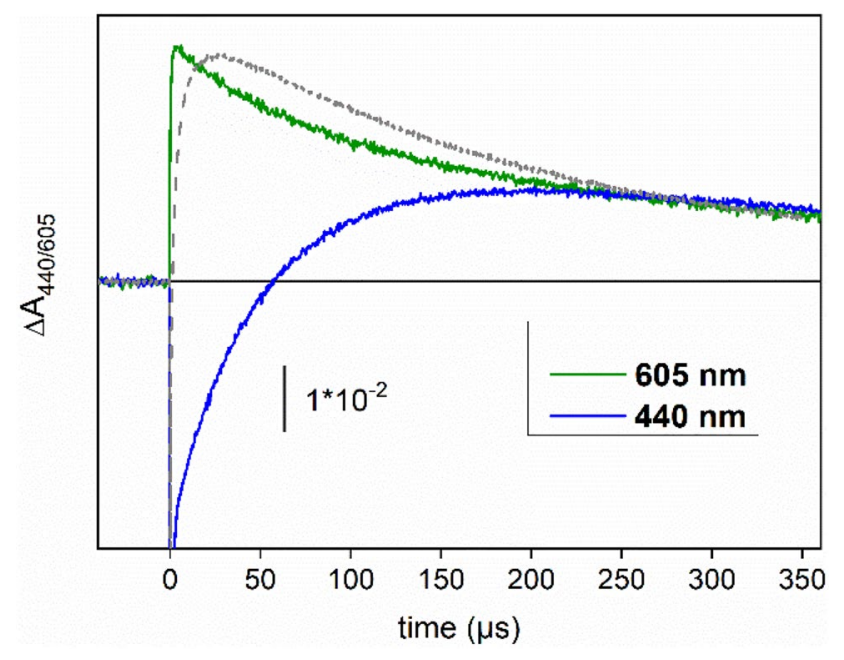

Fig. 2 Transient absorption kinetics at $605 \mathrm{~nm}$ and at $440 \mathrm{~nm}$ for complex 3 in $\mathrm{CH}_{3} \mathrm{CN}$ in presence of $25 \mathrm{mM} \mathrm{MV}^{2+}$. Gray dashed trace shows the kinetics at $440 \mathrm{~nm}$ for complex 1 for comparison. For kinetic analysis see Fig. S5

Laser flash spectroscopy of $\mathbf{3}$ in presence of $\mathrm{MV}^{2+}$ shows that the same radical is formed (Fig. S7, S8). However, in presence of the $\mathrm{Zn}$ ion in $\mathbf{3}$ a ten-fold slower kinetics ( $46 \mu \mathrm{s})$ for this internal electron transfer is observed (Fig. 2, compare blue trace and dashed gray trace). Considering that the electrochemical data indicate a similar driving force for imidazole oxidation by $\mathrm{Ru}^{\mathrm{III}}$ for $\mathbf{1}$ and $\mathbf{3}$ such an observation suggests that in these complexes the oxidation of the imidazole is not pure ET but possibly has to be described by a proton-coupled electron transfer (PCET) process involving deprotonation of the imidazole which could control the kinetics. To interrogate this issue, we performed experiments in presence of different bases (pyridine, lutidine or imidazole). Indeed, addition of a base led to a prominent acceleration of imidazole oxidation (Fig S9, S11). The observed rate of imidazole oxidation is close to the diffusion limit for the base indicating that encounter of the complex with the external base is the rate-limitingstep. This implies that the deprotonation process is energetically favorable requiring that the $\mathrm{p} K_{\mathrm{a}}$ of the oxidized imidazole unit is $\leq 12.5$, the $\mathrm{p} K_{\mathrm{a}}$ of pyridine, the weakest base used [24-26]. Similar acceleration is also observed upon addition of water (Fig S10). However, much higher concentrations are required to obtain comparable accelerations because water is a weaker base (Fig. S11). In the absence of added base, deprotonation of the imidazole likely involves the solvent, which is weakly basic, or residual water. The slower rate of formation of the Im radical in complex $\mathbf{3}$ compared to complex $\mathbf{1}$ could then stem from a less acidic $\mathrm{p} K_{\mathrm{a}}$ of the imidazole when a divalent metal ion is present in the terpyridine cavity. Ground state titrations with external base were performed and indicated similar $\mathrm{p} K_{\mathrm{a}}$ values of 19.6-20 for the deprotonation of the imidazole for all complexes (Fig. S13). Therefore, we favor an alternative explanation where the pyridines of the uncoordinated terpyridine in $\mathbf{1}$ could function as internal base accepting the proton from the oxidized imidazole, probably via trace water molecules, in a similar way to recent findings on a free-base porphyrin-imidazole-phenol system [12]. This function is not available when a metal ion is coordinated (in 3 and 2). Recapitulating the main photophysical events in $\mathbf{3}$ we find that the oxidative quenching of the $\mathrm{Ru}(\mathrm{II})^{*}$ excited triplet state by methyl viologen leads to the formation of the oxidized $\mathrm{Ru}(\mathrm{III})$ that is reset to its original $\mathrm{Ru}(\mathrm{II})$ state through an internal electron transfer process from the redoxactive fused imidazole motif lying between the two metal ions to generate the corresponding imidazole radical. The rate of this electron transfer process is controlled by transfer of the imidazole proton to an available proton acceptor and the product is the neutral imidazolyl radical characterized by a strong absorption band around $440 \mathrm{~nm}$ and a weaker absorption band at $630 \mathrm{~nm}$.

After characterization of light-induced ET in the reference compound $\mathbf{3}$ we turned our attention to $\mathbf{2}$ which holds an additional oxidizable center beside the imidazole, i.e., a $\mathrm{Mn}^{\mathrm{II}}$ ion lodged in the terpyridine cavity. From the electrochemical pattern we can expect that the photogeneration of the ruthenium (III) state of the chromophore in presence of an electron acceptor may lead to an ET cascade with intramolecular oxidation of the imidazole fragment followed by a subsequent charge shift to the manganese (II) center forming $\mathrm{Mn}^{\mathrm{III}}$. A kinetic requirement for $\mathrm{Mn}$ oxidation to effectively occur is that the internal ET is faster than back ET from the reduced electron acceptor. Unfortunately, the oxidation of $\mathrm{Mn}^{\mathrm{II}}$ to $\mathrm{Mn}^{\mathrm{III}}$ is not accompanied by detectable electronic absorption changes in the visible region, henceforth electron transfer from $\mathrm{Mn}^{\mathrm{II}}$ to the oxidized imidazole relies solely on the follow up of the spectroscopic signature of the imidazole and methyl viologen radicals to identify the location of the positive and negative charges resulting from light-induced charge separation. ${ }^{2}$ Successful Mn oxidation then should appear as a decay of the spectral features of the imidazolyl radical which is faster in complex 2 than in complex $\mathbf{3}$, and in particular is faster than the decay of spectral features related to the $\mathrm{MV}^{\bullet+}$ radical.

The transient absorption changes in $\mathbf{2}$ in neat acetonitrile are shown in Fig. 3A. As can be seen, formation of an imidazole radical is clearly detected by the fast recovery of the $\mathrm{Ru}^{\mathrm{III}}$ bleaching and build-up of positive absorption at $440 \mathrm{~nm}$ but with only less than half the maximum amplitude

\footnotetext{
${ }^{2}$ Light-induced Mn oxidation in this kind of complexes has been demonstrated by EPR measurements in presence of irreversible electron acceptors. $[17,18]$ However, in these studies $\mathrm{Mn}^{\mathrm{III}}$ formation is not time-resolved and therefore the detection of Mn oxidation is not a proof for the occurrence of intramolecular ET.
} 

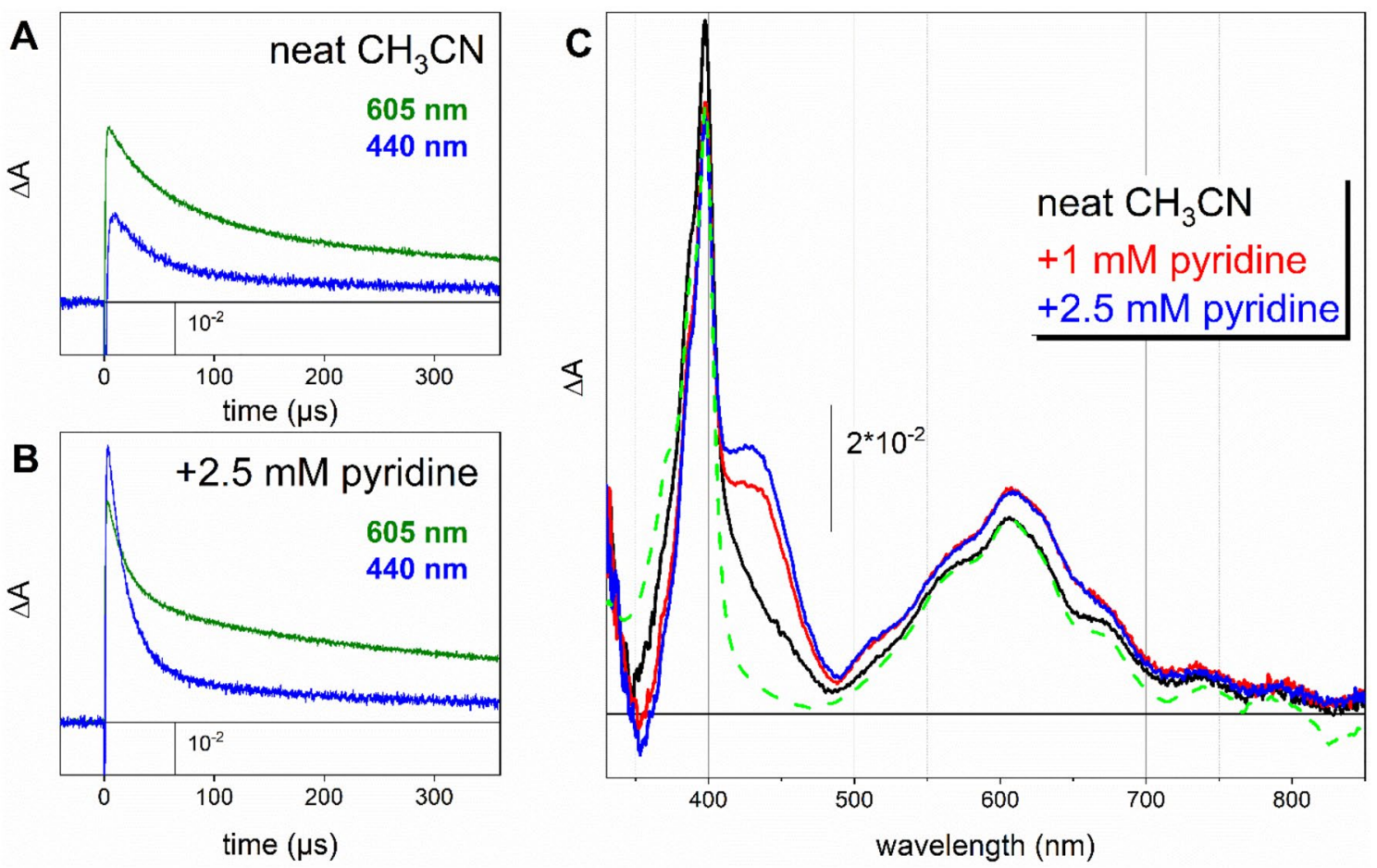

Fig. 3 A, B: Transient absorption kinetics at $605 \mathrm{~nm}$ and at $440 \mathrm{~nm}$ for complex 2 in $\mathrm{CH}_{3} \mathrm{CN}$ in presence of $20 \mathrm{mM} \mathrm{MV}{ }^{2+}$. $\mathbf{A}$ in the absence of base; $\mathbf{B}$ in presence of $2.5 \mathrm{mM}$ pyridine (see Fig. S12 for a kinetic fit). The partial fast decay of the $605 \mathrm{~nm}$ transient in presence of base can be attributed to the absorption of the Im- radical at this wavelength (see inset of Fig. 1B, Fig. S8). C Transient absorp-

compared to complexes $\mathbf{1}$ and $\mathbf{3}$. To rule out that this diminished formation of the imidazole radical is due to the decoordinated form, i.e., where $\mathrm{Mn}^{\mathrm{II}}$ was lost from the terpyridine coordinating cleft, we performed the same experiment with an added excess of $\mathrm{MnCl}_{2}$ salt. No changes in the spectral features and kinetics were observed pertaining the fact that the imidazole radical signature stems from the dinuclear Ru-Mn complex 2. Furthermore, the decay of the imidazole radical was found to be hardly faster than the decay of $\mathrm{MV}^{\bullet+}$ (Fig. 3A) indicating that no or only very slow oxidation of the $\mathrm{Mn}^{\mathrm{II}}$ unit occurs. Interestingly, here too, we found that addition of a base leads to striking changes in the evolution of the system (Fig. 3B, C). As already observed for complex 3 , the formation of the imidazole radical is accelerated in presence of pyridine as external proton acceptor. More importantly, and in sharp contrast with $\mathbf{3}$ where no further redox-active unit is present, the decay of the imidazolyl radical in $\mathbf{2}$ is significantly accelerated to $17 \mu$ s (Fig. S12) and is indeed much faster than the disappearance of the reduced form of the electron acceptor, $\mathrm{MV}^{\bullet+}$ (Fig. 3B). These distinct differences in the decay times together with the snapshot of the imidazolyl radical spectral features support the conclusion that disappearance of the imidazolyl radical is tion spectra of complex 2 taken $10 \mu$ s after laser excitation in $\mathrm{CH}_{3} \mathrm{CN}$ in presence of $20 \mathrm{mM}$ methyl viologen as electron acceptor without external base (black) and after addition of $1 \mathrm{mM}$ (red) and $2.5 \mathrm{mM}$ (blue) pyridine. The green dashed line shows the spectrum of $\mathrm{MV}^{\bullet+}$ for comparison

caused by an intramolecular electron transfer from $\mathrm{Mn}^{\mathrm{II}}$ yielding $\mathrm{Mn}^{\mathrm{III}}$.

To get more insight into the reaction mechanisms relevant for the function of the imidazole group as electron relay, the flash-induced kinetics were recorded at various concentration of base (Fig. 4A, B). The transient concentration of imidazolyl radical increases with increasing concentration of base up to $c a .5 \mathrm{mM}$ pyridine without significant change in the decay kinetics. At these low concentrations of pyridine, the imidazole is not deprotonated to a significant extent in the GS as can be concluded from the titration experiments with imidazole, a much stronger base (Fig. S13). Two further observations are worth mentioning. First, the decay of the imidazolyl absorption at $440 \mathrm{~nm}$ shows a minor, long-lived component in presence of base (Fig. 4A). This could be indicative for establishment of an ET equilibrium due to a reduced driving force for oxidation of $\mathrm{Mn}^{\mathrm{II}}$ by the deprotonated imidazole radical. Second, the rate of charge recombination is strongly decreased already for the lowest concentration of base (Fig. 4B) indicating that the rate of back electron transfer (BET) from $\mathrm{MV}^{\bullet+}$ is significantly slowed down when the imidazole radical is deprotonated. To test this hypothesis, we investigated the effect of the conjugated acid of the external base by adding increasing 

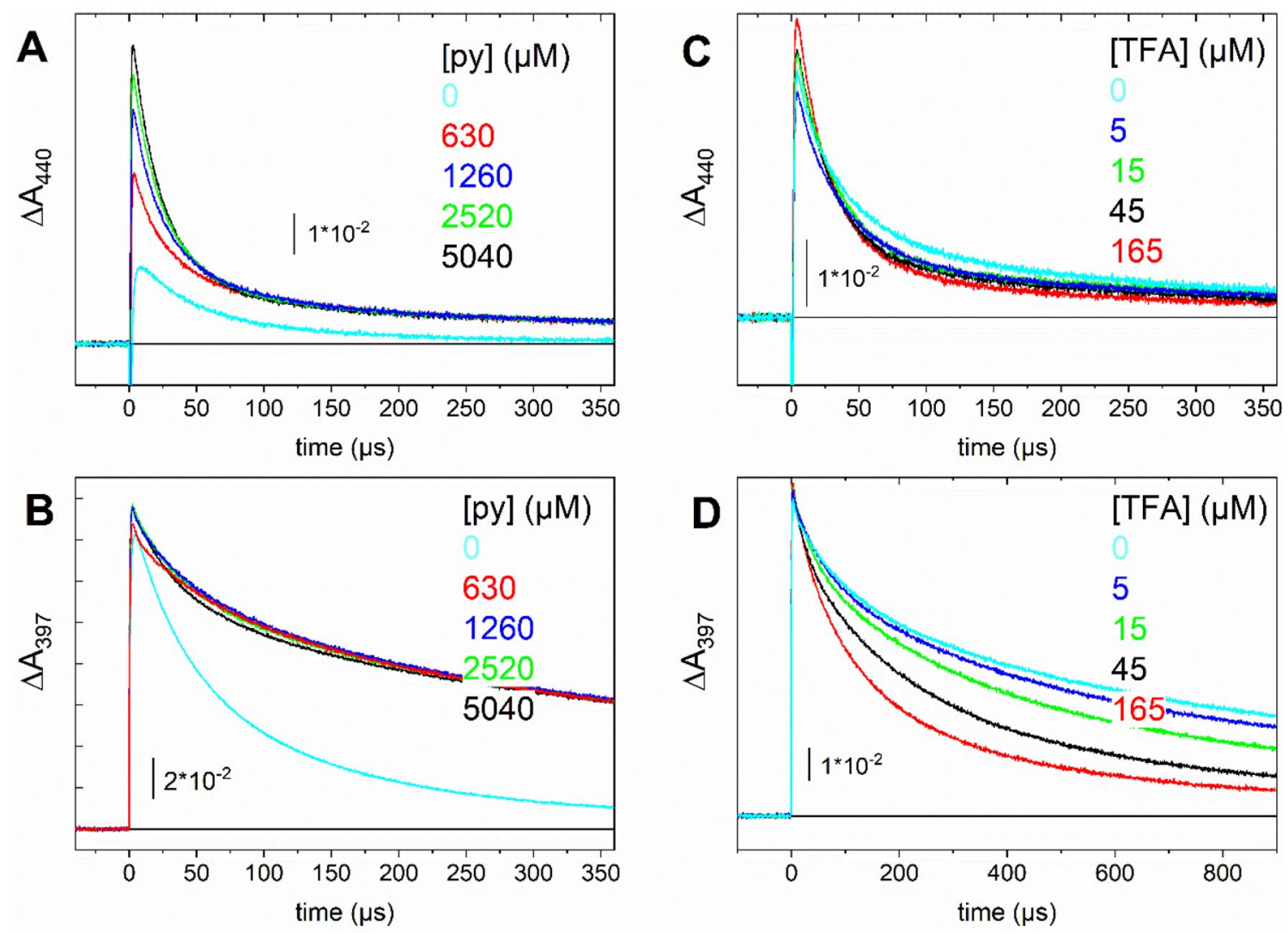

Fig. 4 A, B Variation of the transient absorption kinetics for complex 2 in $\mathrm{CH}_{3} \mathrm{CN}$ in presence of $25 \mathrm{mM} \mathrm{MV}^{2+}$ at $\mathbf{A} 440 \mathrm{~nm}$ and $\mathbf{B} 397 \mathrm{~nm}$ with increasing concentration of pyridine as indicated. $\mathbf{C}, \mathbf{D}$ in presence of $2.5 \mathrm{mM}$ pyridine and with increasing concentration of TFA as indicated

amounts of TFA ( $\mathrm{p} K_{\mathrm{a}}=12.7$ ) [25] to protonate part of the pyridine added. The data in Fig. 4C, D confirm the proposed interpretation. The increased availability of protons leads to an increased driving force for the oxidation of $\mathrm{Mn}^{\mathrm{II}}$ as shown by the faster and more complete decay of the imidazolyl radical signature (Fig. 4C) and re-establishes faster BET from the reduced electron acceptor as seen from the accelerated decay of the latter (Fig. 4D).

\section{Discussion}

Our transient absorption studies of a supramolecular assembly based on a ruthenium chromophore covalently tethered to a manganese (II)-based metal complex through an imidazole fragment allowed clearly to identify the implication of the imidazole unit as electron relay. At the same time, there are strong indications for a crucial role of the imidazole proton in the process. In the following we will try to rationalize the various experimental observations based on a two-dimensional reaction scheme which considers the possible electron and proton transfer events (Scheme 2).

\subsection{Acid-base properties of the complexes}

The ground state $\mathrm{p} K_{\mathrm{a}}$ in $\mathrm{CH}_{3} \mathrm{CN}$ of the imidazole motif was estimated from titration with imidazole as relatively strong external base ( $\mathrm{p} K_{\mathrm{a}}=17.1$ in $\mathrm{CH}_{3} \mathrm{CN}$ ) [25] as described above (Fig. S13 and details on data analysis in the SI). The GS p $K_{\mathrm{a}}$ value of the imidazole group is about $19.8 \pm 0.3$ in the three complexes. Furthermore, a photoacid behavior of complexes bearing an imidazole unit fused to a ruthenium chromophore has been reported in the literature [14, 27]. This property appears amplified in presence of ester-substituted bipyridine ligands, as clearly evidenced by the observed reversible flash-induced deprotonation of complex 3 in presence of a base, visible as a red-shift of the MLCT band of the ruthenium chromophore (Fig. S14). A value of $\mathrm{p} K_{\mathrm{a}}{ }^{*}=18.8$ for deprotonation of the complex in the excited state can be estimated from the 10-15 nm red-shift of the MLCT absorption band [28, 29] (Fig. S13, S14) indicating a decrease by $1 \pm 0.2$ units compared to the GS. We attribute this photoacid behavior to electrostatic interaction $(c a .70 \mathrm{meV})$ between the positive charge density on the $\mathrm{Ru}^{\mathrm{III}}$ ion in the excited state of the chromophore [14] and the phenanthroline-imidazole motif. In presence of a base, deprotonation of the 


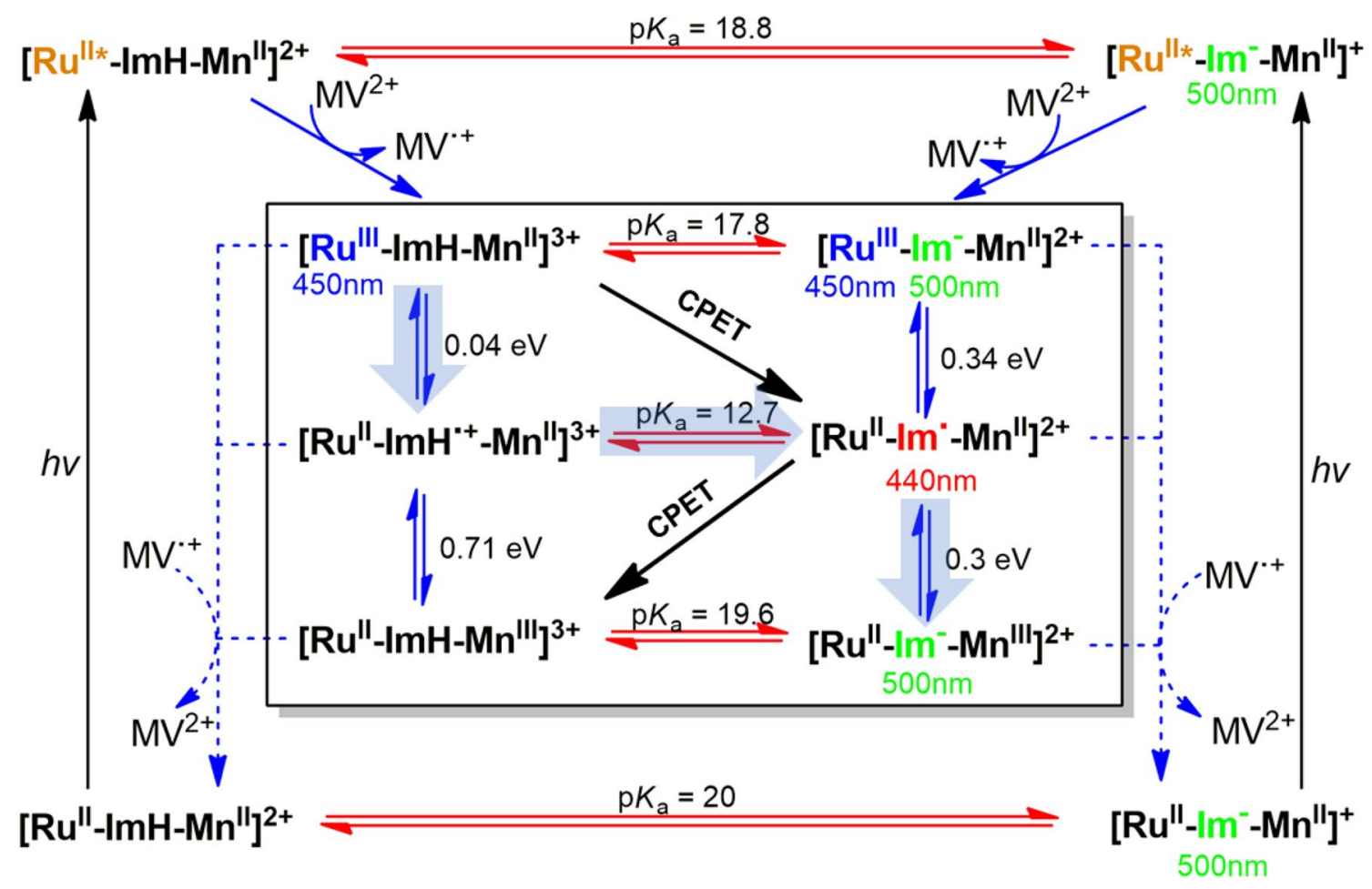

Scheme 2. Proposed reaction scheme for electron and proton transfer in the triad 2 showing the two protonation states for the ground state (bottom), the excited state (top) and the three oxidized states (center box) with the positive charge located at the level of the Ru chromophore, the imidazole electron relay, and the Mn center, respectively (from top to bottom). The imidazole proton is explicitly indicated to distinguish the single protonated $(\mathrm{ImH})$ from the deprotonated form $\left(\mathrm{Im}^{-}\right.$, imidazolate). $\mathrm{ImH}^{\bullet+}$ and $\mathrm{Im}^{\bullet}$ designate the protonated and deprotonated imidazolyl radical, respectively. Spectroscopically

imidazole function can compete with the intrinsic decay of the excited state leading to a shortening of the excited state lifetime and reduction of the emission yield (Fig. S15) via rapid oxidation of the formed imidazolate by the Ru excited state. This charge separation event produces the reduced state of the chromophore, $\mathrm{Ru}(\mathrm{I})$, and the imidazolyl radical. Rapid back ET from the strong reductant $\mathrm{Ru}(\mathrm{I})$ to the imidazolyl radical then brings the system back to the original redox state. ${ }^{3}$ It should be further noticed that the red-shift of the MLCT band caused by deprotonation of the imidazole group shows up in difference spectra as a characteristic absorption peak at $500 \mathrm{~nm}$ making this wavelength a useful spectroscopic marker for the imidazolate state. We assume that the $\mathrm{p} K_{\mathrm{a}}$ values of the GS and excited state are identical for $\mathbf{2}$ and $\mathbf{3}$ and use these values in Scheme 2. The $\mathrm{p} K_{\mathrm{a}}$ values of the imidazole in the three oxidized states of $\mathbf{2}$, however,

\footnotetext{
3 The same mechanism explains the absence of emission when the imidazole group is deprotonated in the GS.[14] The photoacid behavior is also the reason why this kind of complexes suffers from strong excited state quenching in aqueous solution.[19].
}

detected intermediates are indicated by color together with the characteristic wavelengths. The thermodynamic quantities $-\Delta G$ and $\mathrm{p} K_{\mathrm{a}}$ refer to $\mathrm{CH}_{3} \mathrm{CN}$ as solvent and are estimated from the electrochemical and base titration studies as described in the text. Highlighted arrow shows pathway observed through the laser flash experiments. The quenching by $\mathrm{MV}^{2+}$ of the excited state in the deprotonated complex (upper right corner) is probably not occuring to a significant extent (see text)

cannot be determined directly and will be deduced in the following section.

\subsection{Driving forces for intramolecular ET}

Continuing with characterization of the thermodynamic parameters of our reaction scheme (Scheme 2) we turn towards determination of the relevant redox potentials of the three redox-active modules to estimate the driving forces governing the two intramolecular ET steps. Although the electrochemical measurements involve accumulation of three positive charges on the molecule (in contrast to the photophysical studies where only one positive charge is present in the system) we assume that they provide approximately correct values for the individual redox potentials thanks to the high concentration of electrolyte minimizing the effect of electrostatic interactions [30]. This assumption should hold for the second oxidation wave describing oxidation of the imidazole group as the phenyl spacer should prevent strong interaction with the electrical charge on the Mn. The potential of the Ru unit, which in the cyclic voltammogram 
is oxidized in presence of oxidized imidazole, could be more susceptible to be affected by electrostatic interactions as the extent of shielding by polar solvents at such short distances has been questioned [31]. This may lead to a possible error for determination of the $\mathrm{Ru}^{\mathrm{III} / \mathrm{II}}$ potential which therefore should be considered with more caution. For the protonated states (left side in Scheme 2) the potentials in Table 1 show a relatively large difference between the $\mathrm{Mn}^{\mathrm{III} / \mathrm{II}}$ and the $\mathrm{Im}^{\bullet+/ 0}$ potentials suggesting a driving force for the ET between these two units of $-\Delta G=0.71 \mathrm{eV}$. In contrast, $\mathrm{CV}$ data show the potentials of the $\mathrm{Ru}^{\mathrm{III} / \mathrm{II}}$ and the $\mathrm{Im}^{\bullet+/ 0}$ species to be rather close (Table 1, Fig. S1) implying a very small driving force of $-\Delta G \approx 0.04 \mathrm{eV}$ for oxidation of the imidazole group by the oxidized photosensitizer.

To estimate the redox potentials for the states involving a deprotonated imidazole group (right side of Scheme 2), cyclic voltammetry was performed in presence of base (Fig. S16). A peak on the anodic scan at $+0.8 \mathrm{~V}$ appearing in presence of base can be safely attributed to the oxidation of the imidazole group coupled to deprotonation of the complex showing that, as expected, the deprotonated imidazole is significantly easier to oxidize than the protonated form. The wave for the $\mathrm{Mn}^{\mathrm{III} / \mathrm{II}}$ couple becomes irreversible but is only slightly shifted from $+0.5 \mathrm{~V}$ to $+0.475 \mathrm{~V}$. Indeed, at the employed low concentration of external base the imidazole is not deprotonated before its oxidation (on the forward scan) but is so on the reversed scan of the CV. Considering the phenyl spacer and the similar GS $\mathrm{p} K_{\mathrm{a}}$ of the imidazole in absence and presence of a metal in the terpyridine cavity, we conclude on weak interaction between these two redox-active groups pertaining to only a minor decrease of the $\mathrm{p} K_{\mathrm{a}}$ of the imidazole group upon Mn oxidation (19.6 compared to 20 for the GS). As a result, the driving force for Mn oxidation by the deprotonated imidazole radical is with $-\Delta G=0.3 \mathrm{eV}$ less than half of that for Mn oxidation by the protonated imidazole radical $(-\Delta G=0.71 \mathrm{eV})$. The $\mathrm{CV}$ wave for the $\mathrm{Ru}{ }^{\mathrm{III} / \mathrm{II}}$ couple shows a more complicated behavior. The reversible wave at $1.25 \mathrm{~V}$ decreases ${ }^{4}$ in presence of base and a quasi-reversible wave with an anodic peak at $1.12 \mathrm{~V}(130 \mathrm{mV})$ increases in amplitude (Fig. S16). We attribute the latter to the $\mathrm{Ru}^{\mathrm{III} / \mathrm{II}}$ couple in the deprotonated complex. Consequently, the driving force for oxidation of the imidazolate by $\mathrm{Ru}^{\mathrm{III}}$ can be estimated to approximately $-\Delta G=0.34 \mathrm{eV}$. With these values for the driving forces, we can use the lower and upper thermochemical cycles in Scheme 2 to deduce the $\mathrm{p} K_{\mathrm{a}}$ of the oxidized imidazole group as 12.7 and the $\mathrm{p} K_{\mathrm{a}}$ of the imidazole in presence of $\mathrm{Ru}^{\mathrm{III}}$ as ca. 17.8 (Scheme 2). The first value is in agreement with

\footnotetext{
4 The persistence of this wave at low concentrations of base could be related to oxidation by $\mathrm{Ru}^{\mathrm{III}}$ of the external imidazole coupled to deprotonation of the latter.
}

the absence of thermodynamic penalty for proton transfer to pyridine as external base discussed above whereas the second value reveals the effect of the presence of $\mathrm{Ru}^{\mathrm{III}}$ on the acidity of the imidazole group as already inferred from the photoacid properties of the complex in the excited state. To summarize this part, the driving forces deduced from the electrochemical characterization allow for an estimation of the $\mathrm{p} K_{\mathrm{a}}$ values of the imidazole unit in the oxidized complex (inner box in Scheme 2). This analysis shows clearly that the imidazole group becomes increasingly acidic when going from the ground to the excited state and further to the oxidized state of $\mathrm{Ru}$ and the imidazole itself.

\subsection{Reaction paths after laser flash excitation}

With the relevant thermodynamic parameters in our reaction scheme determined we can go on to analyze the dynamics of the flash-induced absorption changes and the reaction sequences operating in our ruthenium-imidazole-terpyMn triad. In absence of external base, the minimal driving force for oxidation of the imidazole group by $\mathrm{Ru}^{\mathrm{III}}$ yields a $\mathrm{Ru}^{\mathrm{III}} \mathrm{Im}^{0} / \mathrm{Ru}^{\mathrm{II}} \mathrm{Im}^{\bullet+}$ equilibrium state without complete oxidation of the imidazole group. This shows up in time-resolved absorption spectra as fast appearance of positive absorption at $440 \mathrm{~nm}$ with similar but not identical shape as the imidazolyl radical formed in presence of base (Fig. S17). It seems likely that $\mathrm{Mn}$ is oxidized from this oxidative equilibrium state but, despite the higher driving force, the ET kinetics is too slow to efficiently compete with BET from the external reversible electron acceptor (Fig. 3A). As no protonation event is involved in the sequence, the imidazole could be replaced by any group with a redox potential between the $\mathrm{Ru}^{\mathrm{III} / \mathrm{II}}$ and $\mathrm{Mn}^{\mathrm{III} / \mathrm{II}}$ couple and its potential adjusted to assure fast reduction of the $\mathrm{Ru}^{\mathrm{III}}$ state. To fulfill the latter requirement, however, some driving force must be sacrificed which might reduce too much the driving force for the following step, at least if the terminal electron donor must have a high redox potential, e.g. for water oxidation.

The situation is more interesting in presence of an external base. In this case we observe fast and complete oxidation of the imidazole group by $\mathrm{Ru}^{\mathrm{III}}$, coupled to deprotonation to form the imidazolyl radical. Scheme 2 shows three different pathways that can be envisioned for the formation of the state $\mathrm{Ru}^{\mathrm{II}}-\mathrm{Im}^{\bullet}-\mathrm{Mn}^{\mathrm{II}}$ from the initial $\mathrm{Ru}^{\mathrm{III}}-\mathrm{ImH}-\mathrm{Mn}^{\mathrm{II}}$ state, oxidation of the imidazole unit followed by deprotonation due to the strongly lowered $\mathrm{p} K_{\mathrm{a}}$ (ETPT), deprotonation by the external base followed by oxidation (PTET), or a concerted mechanism (CPET). Usually in such systems the sequential pathways involve a first, energetically unfavorable step followed by a second, energetically strongly downhill process and determination of the operating pathway is often difficult [32, 33]. In our case we favor the ETPT mechanism based on the observation of fast partial imidazole oxidation 
Scheme 3. Simplified reaction scheme for Mn oxidation in the triad $\mathbf{2}$ showing explicitly the external base (B). The $\Delta \mathrm{p} K_{\mathrm{a}}$ values refer to the difference between the $\mathrm{p} K_{\mathrm{a}}$ of the imidazole electron relay and the external base. For the bases used in this work $\left(\mathrm{p} K_{\mathrm{a}}=12\right.$. $5 \ldots 17.1$ ) this gives approximately $\Delta \mathrm{p} K_{\mathrm{a}} \approx 0 \ldots-5$ and $\Delta \mathrm{p} K_{\mathrm{a}}{ }^{\prime} \approx+7 \ldots+2$

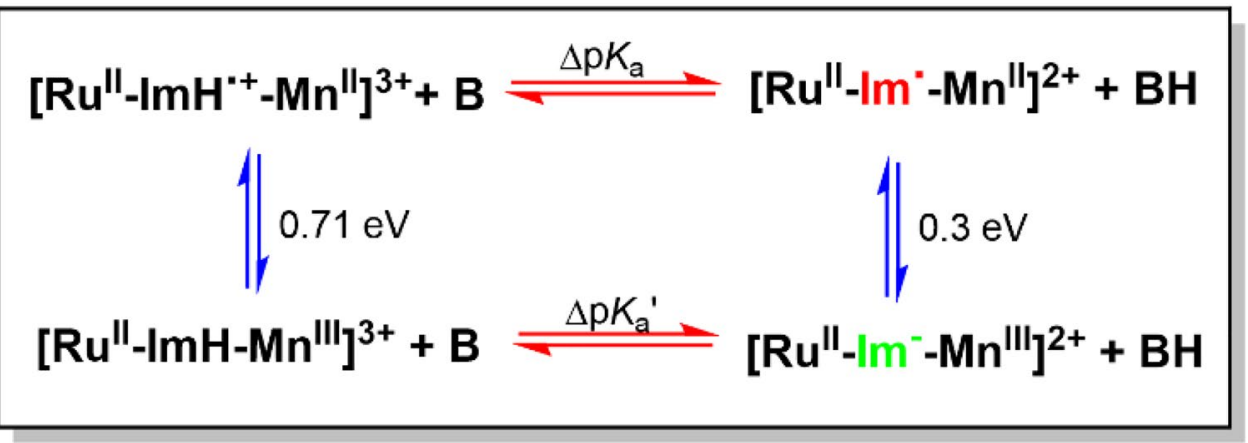

in the absence of base (Fig. 3A) and the fact that in presence of base the rate of $\mathrm{Im}^{\bullet}$ formation is limited by diffusion of the base (Fig. S11).

Compared to the case in absence of base, the deprotonated $\mathrm{Im}^{\bullet}$ radical has lost oxidative power but is still able to oxidize the $\mathrm{Mn}^{\mathrm{II}}$ ion in the terpyridine cavity. Interestingly, the kinetics of decay of the $\mathrm{Im}^{\bullet}$ radical is accelerated in presence of protonated base (Fig. 4C) suggesting that Mn oxidation is to some extent controlled by the concentration of protons in the external medium. To visualize the mechanism proposed to explain this behavior, the reaction steps involved and the interactions of the system with the external base are presented in Scheme 3. It can easily be seen that an increased concentration of protonated base $(\mathrm{BH})$ will shift the reaction towards the more oxidizing $\mathrm{ImH}^{\bullet+}$ species leading to an increased rate of Mn oxidation. In contrast to a pure redox ET relay, the acid/base equilibria of (de)protonatable electron relays lead to coupling of the apparent potential of the electron relay with the protonic conditions in the external medium ( $\mathrm{pH}$ for aqueous buffers). If we take catalysis of water oxidation by a Mn catalyst as example for a process that requires more oxidizing potentials at lower $\mathrm{pH}$, this property of an electron relay enables it to provide relatively constant driving force for activation of the catalyst.

If our interpretation is correct, we should detect, upon Mn oxidation in $\mathbf{2}$, formation of imidazolate to a larger extent in absence of protonated base and less of it in presence of protonated base. This is indeed the case. First, the distinct absorption features observed around $500 \mathrm{~nm}$ in the difference spectra recorded in presence of external base show formation of the imidazolate species (Fig. S17). Second, the transient absorption kinetics at $500 \mathrm{~nm}$ (Fig. S19) show the imidazolate signal rising with a rate corresponding to the rate of $\mathrm{Mn}$ oxidation $(\approx 20 \mu \mathrm{s})$ and with a decay that is accelerated with increasing concentration of acid. Both facts are in agreement with the proposed scenario. Similar, though weaker formation of imidazolate was also found in the reference complex 3 (Fig. S18), a fact that appears surprising at first sight. In this case, the imidazolate is rising due to the BET from $\mathrm{MV}^{\bullet+}$ to the Im radical occurring before or simultaneously with back proton transfer from the protonated form of the proton acceptor (pyH), present at a low concentration $(\approx 2 \mu \mathrm{M})$. When the concentration of protonated base is much higher, reprotonation occurs faster than BET shunting the buildup of imidazolate, (Fig. S20).

A striking observation is that, in contrast to $\mathbf{3}$, in the Mn-containing complex 2 the BET kinetics in presence of base is significantly slower than in absence of base, but faster BET is recovered when acid (pyridinium) is present (Fig. 4B, D). Driving force seems not the determining factor with $-\Delta G \approx-0.95 \mathrm{eV}$ for BET from $\mathrm{MV}^{\bullet+}$ to $\mathrm{Mn}^{\mathrm{III}}$ being very similar for the two protonation states of the imidazole. A decreased bimolecular rate for interaction of the methyl viologen radical with the deprotonated complex could explain the observed trend but the molecular basis of such an effect remains unclear. Alternatively, BET could occur via a slower, concerted CPET mechanism as found in a Ru-Im-phenol system [10]. These aspects would merit a more detailed investigation. We note that slow BET occurs after relatively fast formation (by internal ET) of an $\mathrm{Im}^{-} \mathrm{Mn}^{\mathrm{III}}$ state that is not in fast equilibrium with the lost proton (protonated external base). In other words, the free energy of the system out-of-equilibrium after flash excitation contains a contribution due to the difference of the $\mathrm{p} K_{\mathrm{a}}$ of the complex (19.6 for the state $\mathrm{Ru}^{\mathrm{II}} \mathrm{ImHMn}{ }^{\mathrm{III}}$, see Scheme 2 ) and the base ( $\mathrm{p} K_{\mathrm{a}}=12.5$ in the case of pyridine), yielding the impressive amount of $420 \mathrm{meV}$ for the out-of-equilibrium proton distribution. This free energy difference corresponds to the difference in oxidation potential of the imidazole group in the two protonation states $(1.21 \mathrm{~V}$ vs $0.8 \mathrm{~V})$. Our kinetic studies thus reveal the importance to consider the exchange of free energy between the photoactivated complexes and the protic environment. The latter defines a reference and controls the protonation equilibrium and thereby the redox potential of the electron relay. Due to the reversibility of proton exchange between the complexes and the solution this can be seen as an energy storage mechanism for the functioning of the electron relay. The energy drop of the complex due to deprotonation following oxidation of the electron relay is not a definitive loss but this energy can be recovered to drive the following ET step leading to Mn oxidation and re-reduction of the electron relay. 


\section{Conclusion}

In this study we have presented a triad featuring an imidazole function between a Ru-type photosensitizer and a terpyridine cavity holding a $\mathrm{Mn}$ ion as a proxy for an oxidation catalyst. Time-resolved spectroscopy, by comparison with reference compounds, has permitted to clearly demonstrate the role of the imidazole as an electron relay in oxidizing the $\mathrm{Mn}$ (II) site with a rather fast rate. Comprehensive analysis of the thermodynamic and kinetic parameters shows that the acid-base properties of this electron relay imply a strong coupling of its function with the surrounding medium. In the natural water-oxidizing photocatalyst PS II, the electron relay between the chromophore and the catalytic center is a tyrosine residue in hydrogen-bonding interaction with a histidine [3]. A "rocking proton" mechanism operating between these two residues has been identified as a crucial feature of this electron relay [34] and a large number of model compounds have been investigated in the last decades [35-40]. However, to the best of our knowledge, this work is the first example where the action of such an intermediate electron relay in a photosensitizer-catalyst assembly has been demonstrated. Several challenges still lie ahead to design a system which compares with its natural model. For functioning in aqueous solution, a better decoupling of the electron relay from the photosensitizer is probably required to avoid quenching of the excited state due to the photoacid effect. The terpyridine-Mn unit should be replaced by a catalyst competent for water oxidation. Such a catalyst would certainly be characterized by a higher oxidation potential which puts more severe constraints on the redox potential of the electron relay. Finally, the ultimate proof for the crucial advantage of an electron relay consists in the demonstration of efficient charge accumulation on the catalytic unit upon excitation of the system by sequential excitation flashes and under conditions of continuous illumination [41].

Supplementary Information The online version contains supplementary material available at https://doi.org/10.1007/s43630-021-00163-2.

Acknowledgements This work has been supported by the French Infrastructure for Integrated Structural Biology (FRISBI) ANR-10INSB-05-01 and by the Region Ile-de-France in the framework of C'Nano IdF. The Conseil Général d'Essonne (ASTRE) is acknowledged. The LABEX CHARMMMAT is also gratefully acknowledged.

\section{Declarations}

Conflict of interest On behalf of all authors, the corresponding author states that there is no conflict of interest.

\section{References}

1. Ibrahim, M., Fransson, T., Chatterjee, R., Cheah, M. H., Hussein, R., Lassalle, L., et al. (2020). Untangling the sequence of events during the $\mathrm{S} 2 \rightarrow \mathrm{S} 3$ transition in photosystem II and implications for the water oxidation mechanism. Proceedings of the National Academy of Sciences of the United States of America, 117(23), 12624-12635. https://doi.org/10.1073/pnas.2000529117

2. Lubitz, W., Chrysina, M., \& Cox, N. (2019). Water oxidation in photosystem II. Photosynthesis Research, 142(1), 105-125. https://doi.org/10.1007/s11120-019-00648-3

3. Styring, S., Sjoholm, J., \& Mamedov, F. (2012). Two tyrosines that changed the world: Interfacing the oxidizing power of photochemistry to water splitting in photosystem II. Biochimica et Biophysica Acta, 1817(1), 76-87. https://doi.org/10.1016/j.bbabio. 2011.03.016

4. Brettel K, Schlodder E, Witt HT (1984) Nanosecond reduction kinetics of photooxidized chlorophyll-aII (P-680) in single flashes as a probe for the electron pathway, $\mathrm{H}+$-release and charge accumulation in the $\mathrm{O} 2$-evolving complex. Biochimica et Biophysica Acta (BBA) Bioenergetics, 766(2):403-415 https://doi.org/10. 1016/0005-2728(84)90256-1

5. Hammarstrom, L., \& Styring, S. (2011). Proton-coupled electron transfer of tyrosines in Photosystem II and model systems for artificial photosynthesis: the role of a redox-active link between catalyst and photosensitizer. Energy \& Environmental Science, 4(7), 2379-2388. https://doi.org/10.1039/c1ee01348c

6. Zhao, Y. X., Swierk, J. R., Megiatto, J. D., Sherman, B., Youngblood, W. J., Qin, D. D., et al. (2012). Improving the efficiency of water splitting in dye-sensitized solar cells by using a biomimetic electron transfer mediator. Proceedings of the National Academy of Sciences of the United States of America, 109(39), 15612-15616

7. Lachaud, T., Quaranta, A., Pellegrin, Y., Dorlet, P., Charlot, M. F., Un, S., et al. (2005). A biomimetic model of the electron transfer between P-680 and the TyrZ-His190 pair of PSII. Angewandte Chemie-International Edition, 44(10), 1536-1540. https://doi.org/ 10.1002/anie. 200461948

8. Moore, G. F., Hambourger, M., Kodis, G., Michl, W., Gust, D., Moore, T. A., et al. (2010). Effects of protonation state on a tyrosine-histidine bioinspired redox mediator. The Journal of Physical Chemistry B, 114(45), 14450-14457. https://doi.org/10.1021/ jp101592m

9. Megiatto, J. D., Jr., Mendez-Hernandez, D. D., Tejeda-Ferrari, M. E., Teillout, A. L., Llansola-Portoles, M. J., Kodis, G., et al. (2014). A bioinspired redox relay that mimics radical interactions of the Tyr-His pairs of photosystem II. Nature Chemistry, 6(5), 423-428. https://doi.org/10.1038/nchem.1862

10. Manbeck, G. F., Fujita, E., \& Concepcion, J. J. (2016). Protoncoupled electron transfer in a strongly coupled photosystem II-inspired chromophore-imidazole-phenol complex: Stepwise oxidation and concerted reduction. Journal of the American Chemical Society, 138(36), 11536-11549. https://doi.org/10.1021/ jacs.6b03506

11. Chen, J., Kuss-Petermann, M., \& Wenger, O. S. (2015). Dependence of reaction rates for bidirectional PCET on the electron donor-electron acceptor distance in phenol- $\mathrm{Ru}\left(2,2^{\prime}\right.$-bipyridine $)$ (3)(2)(+) dyads. The Journal of Physical Chemistry B, 119(6), 2263-2273. https://doi.org/10.1021/jp506087t

12. Chararalambidis, G., Das, S., Trapali, A., Quaranta, A., Orio, M., Halime, Z., et al. (2018). Water molecules gating a photoinduced one-electron two-protons transfer in a tyrosine/histidine (Tyr/His) model of photosystem II. Angewandte Chemie (International ed. in English), 57(29), 9013-9017. https://doi.org/10.1002/anie. 201804498 
13. Herrero, C., Quaranta, A., Leibl, W., Rutherford, A. W., \& Aukauloo, A. (2011). Artificial photosynthetic systems. Using light and water to provide electrons and protons for the synthesis of a fuel. Energy \& Environmental Science, 4(7), 2353-2365. https://doi. org/10.1039/c0ee00645a

14. Quaranta, A., Lachaud, F., Herrero, C., Guillot, R., Charlot, M. F., Leibl, W., et al. (2007). Influence of the protonic state of an imidazole-containing ligand on the electrochemical and photophysical properties of a Ruthenium(II)Polypyridine-type complex. Chemistry-a European Journal, 13(29), 8201-8211. https://doi. org/10.1002/chem.200700185

15. Limburg, J., Vrettos, J. S., Chen, H., de Paula, J. C., Crabtree, R. H., \& Brudvig, G. W. (2001). Characterization of the O(2)evolving reaction catalyzed by [(terpy)(H2O) $\mathrm{Mn}(\mathrm{III})(\mathrm{O}) 2 \mathrm{Mn}(\mathrm{IV})$ $(\mathrm{OH} 2)$ (terpy)](NO3)3 (terpy $=2,2^{\prime}: 6,2^{\prime \prime}$-terpyridine). Journal of the American Chemical Society, 123(3), 423-430. https://doi.org/ 10.1021/ja001090a

16. Chen, H., Tagore, R., Das, S., Incarvito, C., Faller, J. W., Crabtree, R. H., et al. (2005). General synthesis of di-mu-oxo dimanganese complexes as functional models for the oxygen evolving complex of photosystem II. Inorganic Chemistry, 44(21), 7661-7670. https://doi.org/10.1021/ic0509940

17. Herrero, C., Quaranta, A., Protti, S., Leibl, W., Rutherford, A. W., Fallahpour, R., et al. (2011). Light-Driven Activation of the [H(2)O(terpy) $\mathrm{Mn}(\mathrm{III})-\mathrm{mu}-(\mathrm{O}(2))-\mathrm{Mn}(\mathrm{IV})($ terpy)OH(2)] Unit in a Chromophore-Catalyst Complex. Chemistry-an Asian Journal, 6(6), 1335-1339. https://doi.org/10.1002/asia.201100030

18. Tebo, A. G., Das, S., Farran, R., Herrero, C., Quaranta, A., Fallahpour, R., et al. (2017). Light-driven electron transfer in a modular assembly of a ruthenium(II) polypyridine sensitiser and a manganese(II) terpyridine unit separated by a redox active linkage. DFT analysis. Comptes Rendus Chimie, 20(3), 323-332. https://doi.org/10.1016/j.crci.2016.08.010

19. Herrero, C., Quaranta, A., Fallahpour, R. A., Leibl, W., \& Aukauloo, A. (2013). Identification of the Different Mechanisms of Activation of a $[\mathrm{Ru}-\mathrm{II}(\mathrm{tpy})(\mathrm{bpy})(\mathrm{OH} 2)](2+)$ Catalyst by Modified Ruthenium Sensitizers in Supramolecular Complexes. Journal of Physical Chemistry C, 117(19), 9605-9612. https://doi.org/10. $1021 / \mathrm{Jp} 4025816$

20. Watanabe, T., \& Honda, K. (1982). Measurement of the extinction coefficient of the methyl viologen cation radical and the efficiency of its formation by semiconductor photocatalysis. The Journal of Physical Chemistry, 86(14), 2617-2619. https://doi.org/10.1021/ j100211a014

21 Qin, X. Z., Liu, A., Trifunac, A. D., \& Krongauz, V. V. (1991). Photodissociation of hexaarylbiimidazole. 1. Triplet-state formation. The Journal of Physical Chemistry, 95(15), 5822-5826. https://doi.org/10.1021/j100168a022

22. Sathe, S. S., Ahn, D., \& Scott, T. F. (2015). Re-examining the photomediated dissociation and recombination kinetics of hexaarylbiimidazoles. Industrial \& Engineering Chemistry Research, 54(16), 4203-4212. https://doi.org/10.1021/ie504230c

23. Coraor, G. R., Riem, R. H., MacLachlan, A., \& Urban, E. J. (1971). Flash photolysis of a substituted hexaarylbiimidazole and reactions of the imidazolyl radical. The Journal of Organic Chemistry, 36(16), 2272-2275. https://doi.org/10.1021/jo00815a016

24 Eigen, M. (1964). Proton transfer, acid-base catalysis, and enzymatic hydrolysis. Part I: ELEMENTARY PROCESSES. Angewandte Chemie International Edition in English, 3(1), 1-19. https://doi.org/10.1002/anie.196400011

25 Nurminen, E. J., Mattinen, J. K., \& Lönnberg, H. (2001). Nucleophilic and acid catalysis in phosphoramidite alcoholysis. Journal of the Chemical Society, Perkin Transactions, 2(11), 2159-2165. https://doi.org/10.1039/B104910K

26. Kaljurand, I., Kutt, A., Soovali, L., Rodima, T., Maemets, V., Leito, I., et al. (2005). Extension of the self-consistent spectrophotometric basicity scale in acetonitrile to a full span of 28 pKa units: Unification of different basicity scales. Journal of Organic Chemistry, 70(3), 1019-1028. https://doi.org/10.1021/ jo048252w

27. Khade, R. V., Dutta Choudhury, S., Pal, H., \& Kumbhar, A. S. (2018). Excited State Interaction of Ruthenium (II) Imidazole Phenanthroline Complex [Ru(bpy)2ipH]2+ with 1,4-Benzoquinone: Simple Electron Transfer or Proton-Coupled Electron Transfer? ChemPhysChem, 19(18), 2380-2388. https://doi.org/ $10.1002 /$ cphc. 201800313

28. Giordano, P. J., Bock, C. R., Wrighton, M. S., Interrante, L. V., \& Williams, R. F. X. (1977). Excited state proton transfer of a metal complex: Determination of the acid dissociation constant for a metal-to-ligand charge transfer state of a ruthenium(II) complex. Journal of the American Chemical Society, 99(9), 3187-3189. https://doi.org/10.1021/ja00451a066

29 Marciniak, B., Kozubek, H., \& Paszyc, S. (1992). Estimation of $\mathrm{pKa}^{*}$ in the first excited singlet state. A physical chemistry experiment that explores acid-base properties in the excited state. Journal of Chemical Education, 69(3), 247. https://doi.org/10.1021/ ed069p247

30. Weller, A. (1982). Photoinduced electron transfer in solution: Exciplex and radical ion pair formation free enthalpies and their solvent dependence. Zeitschrift für Physikalische Chemie, 133(1), 93-98. https://doi.org/10.1524/zpch.1982.133.1.093

31. Rumble, C. A., Licari, G., \& Vauthey, E. (2020). Molecular dynamics simulations of bimolecular electron transfer: Testing the coulomb term in the weller equation. The Journal of Physical Chemistry B, 124(44), 9945-9950. https://doi.org/10.1021/acs. jpcb.0c09031

32. Tyburski, R., Liu, T., Glover, S. D., \& Hammarstrom, L. (2021). Proton-coupled electron transfer guidelines, fair and square. Journal of the American Chemical Society, 143(2), 560-576. https:// doi.org/10.1021/jacs.0c09106

33 Mayer, J. M., \& Rhile, I. J. (2004). Thermodynamics and kinetics of proton-coupled electron transfer: stepwise vs.concerted pathways. Biochimica et Biophysica Acta, 1655(1-3), 51-58. https:// doi.org/10.1016/j.bbabio.2003.07.002

34. Tommos, C., \& Babcock, G. T. (2000). Proton and hydrogen currents in photosynthetic water oxidation. Biochimica et Biophysica Acta, 1458(1), 199-219. https://doi.org/10.1016/s0005-2728(00) 00069-4

35. Yoneda, Y., Mora, S. J., Shee, J., Wadsworth, B. L., Arsenault, E. A., Hait, D., et al. (2021). Electron-nuclear dynamics accompanying proton-coupled electron transfer. Journal of the American Chemical Society, 143(8), 3104-3112. https://doi.org/10.1021/ jacs.0c10626

36. Huynh, M. T., Mora, S. J., Villalba, M., Tejeda-Ferrari, M. E., Liddell, P. A., Cherry, B. R., et al. (2017). Concerted one-electron two-proton transfer processes in models inspired by the Tyr-his couple of photosystem II. ACS Central Science, 3(5), 372-380. https://doi.org/10.1021/acscentsci.7b00125

37. Zhang, M.-T., Irebo, T., Johansson, O., \& Hammarström, L. (2011). Proton-coupled electron transfer from tyrosine: A strong rate dependence on intramolecular proton transfer distance. Journal of the American Chemical Society, 133(34), 13224-13227. https://doi.org/10.1021/ja203483j

38. Hammarström, L., \& Styring, S. (2011). Proton-coupled electron transfer of tyrosines in Photosystem II and model systems for artificial photosynthesis: the role of a redox-active link between catalyst and photosensitizer. Energy \& Environmental Science, 4(7), 2379-2388. https://doi.org/10.1039/C1EE01348C

39. Irebo, T., Reece, S. Y., Sjödin, M., Nocera, D. G., \& Hammarström, L. (2007). Proton-coupled electron transfer of tyrosine oxidation: Buffer dependence and parallel mechanisms. Journal 
of the American Chemical Society, 129(50), 15462-15464. https:// doi.org/10.1021/ja073012u

40. Magnuson, A., Berglund, H., Korall, P., Hammarstrom, L., Akermark, B., Styring, S., et al. (1997). Mimicking electron transfer reactions in photosystem II: Synthesis and photochemical characterization of a ruthenium(II) tris(bipyridyl) complex with a covalently linked tyrosine. Journal of the American Chemical Society, 119(44), 10720-10725.

41 Karlsson, S., Boixel, J., Pellegrin, Y., Blart, E., Becker, H.-C., Odobel, F., et al. (2012). Accumulative electron transfer: Multiple charge separation in artificial photosynthesis. Faraday Discussions, 155, 233-252. https://doi.org/10.1039/C1FD00089F

\section{Authors and Affiliations}

\section{Philipp Gotico ${ }^{1}$ Christian Herrero ${ }^{2}$. Stefano Protti ${ }^{3}$. Annamaria Quaranta ${ }^{1}$ - Sujitraj Sheth ${ }^{1} \cdot$ Reza Fallahpour $^{4}$. Rajaa Farran ${ }^{1,5} \cdot$ Zakaria Halime $^{2} \cdot$ Marie Sircoglou $^{2} \cdot$ Ally Aukauloo $^{2} \cdot$ Winfried Leibl ${ }^{1}$ (b)}

1 Institut de Biologie Intégrative de La Cellule (I2BC), Université Paris Saclay, CEA, CNRS, 91191 Gif-sur-Yvette, France

2 Institut de Chimie Moléculaire Et Des Matériaux d'Orsay (ICMMO), Université Paris Saclay, 91405 Orsay, France

3 PhotoGreen Lab, Department of Chemistry, University of Pavia, 27100 Pavia, Italy
4 Department of Chemistry, University of Zürich UZH, Freiestrasse 3, CH-3012 Bern, Switzerland

5 Lebanese International University, Mazraa, Beirut 146404, Lebanon 